\title{
In adults: $47.2 \%$ have periodontitis! How about in orthodontic patients?
}

\author{
Alberto Consolaro ${ }^{1}$
}

The occurrence of chronic inflammatory periodontal disease due to dental plaque in adults over 30 years of age was noticed in $47.2 \%$ of the 3,742 subjects studied, representing a 64.7 million people population in the 50 states of the U.S. and the District of Columbia. The methods used by the authors were uniquely precise and the results brought us to great insight on the correlation between orthodontic treatment and periodontal health, which is described below.

Keywords: Orthodontics. Periodontics. Gingivitis. Periodontitis.

A prevalência de $47,2 \%$ da doença periodontal inflamatória crônica induzida pela placa dentobacteriana em adultos com mais de 30 anos foi detectada em 3.742 adultos, que representaram estatisticamente 64,7 milhões de pessoas de 50 estados e do distrito federal dos Estados Unidos da América. O método foi preciso e os resultados induzem a alguns insights quanto à relação entre o tratamento ortodôntico e a saúde dos tecidos periodontais, que foram expostos no texto desse trabalho.

Palavras-chave: Ortodontia-Periodontia. Gengivite. Periodontite.

\section{INTRODUCTION}

When the media splashed headlines with the results of a research conducted by the Division of Oral Health at the Centers for Disease Control and Prevention (CDC), Atlanta, GA in association with other academic institutions, which stated that almost half of the American adult population (30 years old or older) have periodontitis, these findings seemed exaggerated, however these results couldn't be more accurate.

Due to its significance, this study was published on the Journal of Dental Research and the authors ${ }^{2}$ analyzed for the first time in dental history a nota-

${ }^{1}$ Full Professor, FOB-USP. Full Professor of the Post-Graduation program, FORP-USP. bly large sample of 3,742 adults over 30 years of age, which represented 64.7 million people population in the 50 states of the U.S. and the District of Columbia. Another important factor is that six sites per tooth were measured for all teeth, excluding third molars. Previous studies on the same topic had significantly smaller sample sizes and measured only a maximum or four sites per tooth, demonstrating a less frequent periodontal disease prevalence in its results. It is safe to say that previous studies underestimated the prevalence of chronic inflammatory periodontal disease. Each person went through a detailed examination and

How to cite this article: Consolaro A. In adults: $47.2 \%$ have periodontitis! How about in orthodontic patients? Dental Press J Orthod. 2013 Jan-Feb;18(1):3-5.

Submitted: November 11, 2012

Revised and accepted: November 17, 2012

Contact address: Alberto Consolaro

E-mail: consolaro@uol.com.br 
the results shocked the lay and scientific community. The results showed that periodontitis affected $47.2 \%$ of the subjects studied, being $8.7 \%$ mild, 30\% moderate and $8.5 \%$ severe types of the disease.

On subjects with 65 years of age or more, $64 \%$ presented with either moderate or severe forms of periodontitis. The media headlines were right when announcing that almost half of adults have periodontitis, which is considered the most complex form of oral disease due to dental plaque in adults.

The following standards were used to define the severity of the periodontitis:

" Severe periodontitis was defined as the presence of 2 or more interproximal sites with at least $6 \mathrm{~mm}$ attachment loss and 1 or more interproximal site(s) with at least $5 \mathrm{~mm}$ pocket depth.

" Moderate periodontitis was defined as 2 or more interproximal sites with at least $4 \mathrm{~mm}$ clinical attachment loss or 2 or more interproximal sites with pocket depth of at least 5 $\mathrm{mm}$, also not on the same tooth.

" Mild periodontitis was defined as at least 2 interproximal sites with a minimum of $3 \mathrm{~mm}$ attachment loss and at least 2 interproximal sites with a minimum of $4 \mathrm{~mm}$ pocket depth or 1 site with a minimum of $5 \mathrm{~mm}$ pocket depth.

Dental decay, gingivitis and periodontitis result from a lack of patient education and poor oral hygiene. This research indicated that periodontitis was significantly higher in less educated, underprivileged male subjects who were current smokers, reaffirming disparities in the burden of periodontitis by sociodemographic segments of the adult U.S. population. Furthermore, Mexican Americans had the highest prevalence of periodontitis, which was significantly higher than Non-Hispanic Caucasians.

To explain the importance of certain oral care products the media has recently illustrated the existence of gum bleeding on an advertisement by pointing out red blood stains left on apples right after people bit into them.

Even thought bleeding is fairly common in gingivitis, it is a remarkable sign of periodontitis. Unfortunately, most people due to lack of motivation or poor awareness struggle brushing their teeth frequently and/or properly, developing more severe types of periodontitis, which require further professional intervention.

\section{PERIODONTAL DISEASE AND ORTHODONTIC TREATMENT: THE INSIGHTS}

We can reasonably exaggerate that if $47 \%$ of adults have periodontitis, the remaining adults have gingivitis, since very few people wouldn't present any gingivitis after detailed examination on six different sites for each tooth. It is unrealistic to imagine a clinical scenario where a patient is completely free of inflammatory infiltrates, even in patients with overall good oral health.

After analyzing the results presented by Eke et $\mathrm{al}^{2}$ we believe some questions and insights should be pondered:

1. What pattern would the prevalence of chronic inflammatory periodontal disease (gingivitis and periodontitis) have in orthodontic patients during treatment?

2. Would the prevalence of chronic inflammatory periodontal disease be larger or smaller in patients who have undergone orthodontic treatment?

3. Does the orthodontic treatment act as a comprehensive and motivating factor for a more efficient oral hygiene and health?

4. Clinicians may have individual opinions, but those are irrelevant to science, what matters to science are the criteria and methods used to obtain results. The material and methods used by Eke et $\mathrm{al}^{2}$ could be used on an active orthodontic treatment population to clarify the influence of orthodontic treatment on periodontal disease.

5. The strongest suit of this research was unquestionably its large sample size and the detailed examination performed, six sites of this analysis for each tooth. The results of this study raise an important question that we should ask ourselves: Do we sufficiently care about the periodontal status of patients during orthodontic treatment?

The distinguishing feature between gingivitis and periodontitis is that the second has loss of the attachment apparatus between tooth and alveolar bone, even if in the beginning it seems to be just a "harmless" gingivitis.

In general, the damage to the attachment apparatus is fundamental to the change of relationship between the junctional epithelium, alveolar bone height and gingival 


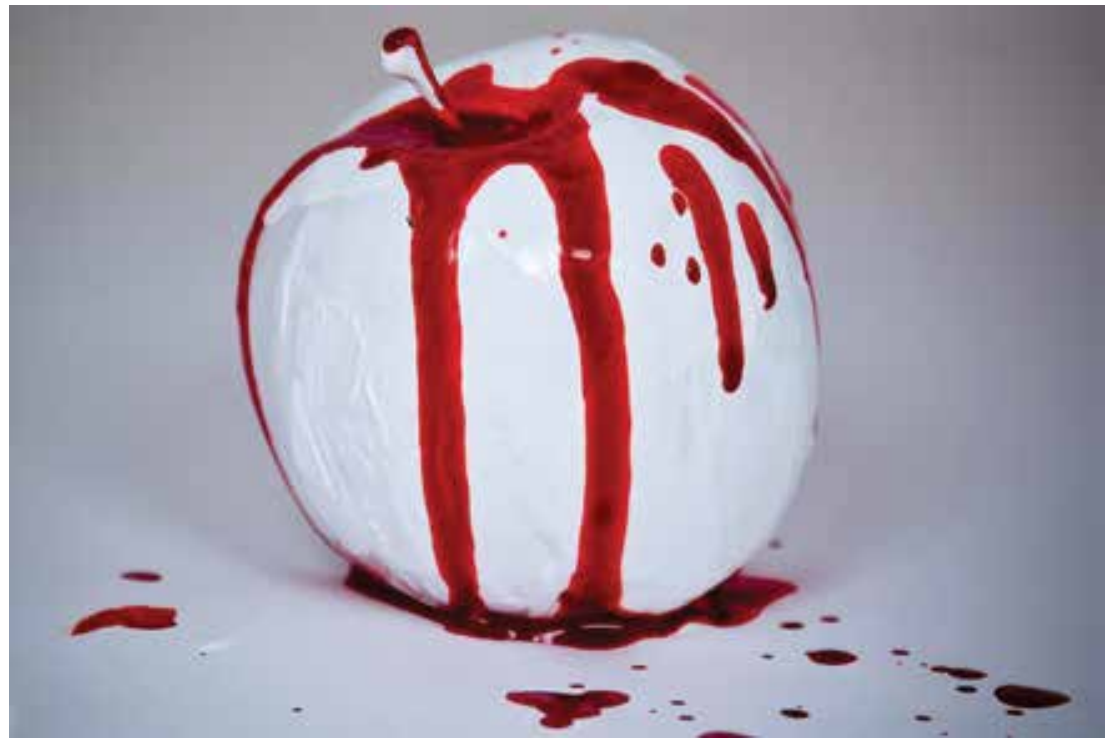

4) If patients undergoing orthodontic treatment present less chronic inflammatory periodontal disease throughout life, it strengthens the importance of orthodontic treatment to achieve longterm oral health stability.

5) On the other hand, if patients undergoing orthodontic treatment present more chronic inflammatory periodontal disease throughout life, it would exalt even more the significance of the orthodontist-periodontist interaction to control and treat mild or incipient periodontal problems before the end of the orthodontic treatment.

sulcus depth. Moreover, investigating and understanding the periodontal status of a patient after orthodontic treatment could reveal important aspects of the orthodontic practice, since many beautifully straight smiles may present some form of periodontitis.

We should also note that:

1) The chronic inflammatory periodontal disease is destructive, asymptomatic, slow and progressive, either continuously or through marked outbreaks. When present, the chronic inflammatory periodontal disease usually affects the patient's oral health for months and/or years. Could the orthodontic treatment improve long-term periodontal health for those patients or not?

2) Human life expectancy is increasing and to ensure quality of life oral health should be maintained for much longer than previously. Would patients present better overall oral health later in life if they had undergone orthodontic treatment at any point in life?

3) The countless benefits of orthodontic treatment are increasingly becoming available to all socio-demographic segments of the population. The socio-demographic segment periodontal burden disparity showed to be the most important aspect on the study of Eke et al. What role does it play in patient's periodontal health during orthodontic treatment?

\section{FINAL CONSIDERATIONS}

The $47.2 \%$ prevalence of chronic inflammatory periodontal disease caused by dental plaque in adults over 30 years of age was measured by Eke et $\mathrm{al}^{2}$ through a precise and innovative method, leading us to great insight on the correlation of orthodontic treatment and periodontal health, which was not yet clearly described in the literature.

REFERENCES

1. Eke PI, Thornton-Evans GO, Wei L, Borgnakke WS, Dye BA. Accuracy of NHANES periodontal examination protocols. J Dent Res. 2010:89(11):1208-13

2. Eke PI, Dye BA, Wei L, Thornton-Evans GO, Genco RJ. Prevalence of periodontitis in adults in the United States: 2009 and 2010. J Dent Res. 2012:91(10):914-20.

3. Hunt RJ. The efficiency of half-mouth examinations in estimating the prevalence of periodontal disease. J Dent Res. 1987;66(5):1044-8

4. Hunt RJ, Fann SJ. Effect of examining half the teeth in a partial periodontal recording of older adults. J Dent Res. 1991;70(10):1380-5

5. Kingman A, Albandar JM. Methodological aspects of epidemiological studies of periodontal diseases. Periodontol 2000. 2002;29:11-30.

6. Kingman A, Morrison E, Löe H, Smith J. Systematic errors in estimating prevalence and severity of periodontal disease. J Periodontol. 1988:59(11):707-13.

7. Kingman A, Susin C, Albandar JM. Effects of partial recordings on severity estimates of periodontal disease. J Clin Periodontol. 2008:35(8):659-67. 